\title{
OPTIMIZATION IN OIL SLICK COMBATING STATIONS ALLOCATION. APPLICATION TO THE SEA OF AZOV
}

\author{
ZAFIRAKOU A.* \\ PALANTZAS G. \\ KARAMBAS Th. \\ KOUTITAS Ch.
}

\author{
Department of Civil Engineering \\ Aristotle University of Thessaloniki \\ 54124 Thessaloniki, Greece
}

Received: $17 / 01 / 2014$

Accepted: 10/03/2014

*to whom all correspondence should be addressed:

Available online: 01/04/2014

e-mail: azafir@civil.auth.gr

\begin{abstract}
A method is presented and preliminarily applied to the optimization of the allocation of oil-slick combating coastal stations in a coastal basin. The decision support methodology is based on the annual simulation of the circulation in the basin according to climatologic data, on the oil spill simulation by the method of Lagrangian particles, on the analysis of the quantified stochastic environmental effects from a number of probable oil spill sources distributed over the basin and on the selection of the optimal coastal oil spill stations. The selection is based on a proposed metric for the operational effectiveness of each station. Using available data, a preliminary application is presented for the Azov Sea, where a number of coastal sites, protected by Ramsar convention, exist and an intensive maritime traffic is planned for the near future.
\end{abstract}

Keywords: oil slick, combating stations, modeling, Azov Sea.

\section{Introduction}

The frequent accidental oil spills, worldwide, originating from oil extraction activities, the oil maritime transport or from ship wreckages, led to the emerging development of contingency plans and to the organization of operational measures for the mitigation of the environmental effects of oil spills reaching the coast. Among other measures, the allocation of "oil spill combating stations", in the form of containers, where the necessary booms, pumps and dispersants are stored, to be transported to the oil spill accident site by special vessels and well trained crews, in the minimum time, is an effective approach.

An optimization problem is designed, regarding the optimal number and the optimal allocation of these stations. The problem is a multi-parametric one, comprising a) a number of probable oil spill generation sites (the sources), b) the existing circulation conditions and current patterns at the time of the accident, c) the environmental effects in case of spill beaching (arrival and trapping of oil masses on a nearby beach) and d) the minimum time required for the specially equipped and trained vessel, to reach the oil spill site, before the spill is dispersed to uncontrollable magnitude.

A methodology, based on the selection of the most probable oil spill generation sources in the basin, the simulation of the main characteristics of the basin, the circulation forcings on an annual basis (the consequent transport by advection and dispersion of oil spills generated throughout the year, from the above sources), and the quantitative estimation of the environmental effects along the coasts from each 
source, is presented here. The method is accomplished with the application of a proposed metric, regarding the operational effectiveness of a number of realistic (candidates) oil spill combating stations. These stations are usually allocated in well-organized coastal locations, where either urban settlements or port facilities exist. The application of that metric, results to the sorting of these stations, on the basis of their operational effectiveness and rationalizes the decision, regarding the selection of a number of them, to be organized and equipped, based on the financial and administrative conditions.

A quite abundant bibliography exists regarding coastal basin circulation models and oil spill transport models. The modeling and simulation used here are based on previously published models, while the simulation results are used in an original way, to conclude on the annual probability of the coastal pollution and the quantification of its environmental effects, according to the ecological sensitivity of the coast.

The application presented here refers to the Azov Sea, a marginal sea to the Black sea, characterized by shallow waters, low extended beaches, prone to trapping the arriving oil. Recently a number of coastal sites in the Azov Sea are designated as protected by the Ramsar convention, as there exist precious wetlands, refuges of rare bird species.

The application is illustrative of the proposed methodology, has a preliminary character based on available data and is planned to be followed by a more detailed study.

\section{Methodology}

Firstly, the main currents-generation-mechanisms have to be recognized and modeled. With regard to the surface currents, their most important components are the wind generated ones, the wave generated Stokes drift and the tidal residual currents, if any. The seasonal thermohaline circulation may be of some importance in special cases. In the case of well mixed shallow basins the last forcing becomes non important. Therefore, barotropic flow models are usually adequate in 3D (depth varying) or $2 \mathrm{DH}$ (depth averaged) forms. The basin response time, i.e. the time required to reach steady flow conditions from a cold start, is compared to the time scale of the synoptic weather variability. If the first is smaller than the second, a series of steady currents patterns can be used for the modeling of the annual circulation. Otherwise the circulation and waves model have to be run for the whole year, in a transient form, following the external wind, tidal and other (like river inflows) forcings.

The 2DH barotropic flow form of the wind generated circulation, comprises the depth mean velocity components $u(x, y, t), v(x, y, t)$ and the free surface elevation $\zeta(x, y, t)$. The classical form of the model has 3 equations, describing the mass conservation and the forces equilibrium in $x, y$ directions. The Coriolis effect is always important. The eddy viscosity can be derived from a turbulence closure model like the $k$ $\varepsilon$ model or equivalently, from the Smagorinsky correlation of the eddy viscosity to the current vorticity. The surface currents can be estimated from their depth mean values, assuming a velocity distribution along the depth (parabolic or logarithmic) following a simple procedure (Koutitas, 1998).

The wave generated transport component in the open sea (far from the breaker zone) refers to the Stokes drift, easily computed from the wave height, the wave period and the wave direction. Those can be computed in transient or steady mode from a number of models, starting with the $1^{\text {st }}$ generation parametric ones, based on empirical relations of fetch, wind intensity and duration and ending with the $3^{\text {rd }}$ generation models, solving the wave energy transport equation (The WAMDIG group, 1988).

As far as it concerns the oil slick transport model, the main processes to be properly modeled, are the advection and diffusion of the oil masses, followed by the evaporation of the lighter fractions. The beaching process, describing the duration of the oil masses adherent to the coast, and the oil quantities that are permanently trapped on the coast, is the second important physical process to be properly modeled.

The oil spill simulation by a large number of passive (not interacting with the existing hydrodynamics) particles, transported in a Lagrangian frame of reference, is the most effective procedure, used in most contemporary models as a) it can describe oil spill geometries and shapes at subgrid level, b) the model 
results are not distorted by numerical errors, like numerical diffusion, and c) the fraction of the initially introduced (at the spill source) particles reaching the coast can be considered as the probability of pollution from a minor spill (Samuels et al., 2013).

The model uses as advective transport factor the interpolated $u, v$ velocity components, from the grid used for the solution of the circulation models, while as diffusive transport factor the eddy (momentum or mass) diffusion parameter, used in the currents models. Each particle represents a specific oil quantity, with specific density, evaporation rate, etc properties. It is obvious that the bigger number of particles is used for the spill simulation, the most accurate the results are. The evaporation effect at the initial stage is simulated by the decrease of the oil mass contained in the evaporable particles. The emulsification effect, at a later stage, is simulated by the increase of the mass of the emulsified particles and their tendency to overcome vertical diffusion and the settlement of solidified oil masses at a final phase, by their sinking to the sea bed due to the increase of their density (Sofianos et al., 2012).

\section{Results and discussion}

\subsection{The operational application and the optimization procedure}

The modeling procedure comprises the synthesis of an annual weather time series (hourly or daily values), the activation of the circulation and wave models for the calculation of the wind, tidal, river inflow and Stokes drift circulation components, and the storing of the results in the form of surface current components and turbulent diffusion coefficient values.

For a specific oil spill source, the daily produced spills are simulated by the introduction to the source coordinates of a number of particles (a specific oil quantity) and their subsequent tracking for the rest of the year, due to the variable current patterns. The beaching of some particles, if any, results to the loading of the specific coastal mesh with the number of the beached particles. At the end of the year, a number of beach meshes are characterized by a number of beached particles, accumulated during the year, representing the probability of oil pollution occurrence $P_{j k}^{i}$ from that spill source, where $i$ is the oil slick source index and $j, k$ the coastal mesh coordinates.

The simulation is repeated for a number of spill sources $(i=1, N)$, according to the maritime transport, or the offshore oil production conditions in the basin. According to the ecological value of each coastal mesh, an ecological weighting factor is applied for each polluted coastal mesh $W_{j k}$.

The number of the coastal meshes polluted from each source and the sum of the products of the pollution probabilities (number of particles beached on that mesh during the year) multiplied by the ecological weighting factor of the polluted coastal mesh, gives the environmental impact of each spill source:

$$
E^{i}=\sum_{j} \sum_{k} P_{j k}^{i} W_{j k}
$$

The number of realistic oil combating stations is fixed, according to the social and industrial conditions in the basin, i.e. the existing coastal settlements, the existing port or coastal industries facilities etc. For those $(m=1, M)$ candidate oil spill combating stations, the operational effectiveness metric, $O_{m}$, is defined as follows. The sum of the fractions having as nominator the ecological impact of each oil spill source, examined previously, and as denominator the distance of an oil spill combating station to that source, gives the operational effectiveness of that station:

$$
\mathrm{O}_{\mathrm{m}}=\sum_{\mathrm{i}=1}^{\mathrm{N}} \mathrm{E}^{\mathrm{i}} / \mathrm{d}_{\mathrm{mi}} \text { for } \mathrm{m}=1 \text { to } \mathrm{M}
$$

where $d_{m i}$ is the distance of station $m$ to the source $i$.

The stations are sorted according to those values and the priority for their organization, equipping and training is decided on those operational effectiveness values. 


\subsection{Application to the sea of Azov}

The Azov Sea is a marginal sea to the Black sea extending over $300 \times 200 \mathrm{~km}$ north of the Kerch straits of the Crimea peninsula. The sea is very shallow (max depth $15 \mathrm{~m}$ ) and the Don river is the dominant fresh water supplier, having a mean annual discharge of $1000 \mathrm{~m}^{3} \mathrm{sec}^{-1}$, with mean summer low of $500 \mathrm{~m}^{3} \mathrm{sec}^{-1}$ and a winter high of $1700 \mathrm{~m}^{3} \mathrm{sec}^{-1}$. A mean annual discharge distribution is assumed for the estimation of the river inflow current component. The tidal contribution, on the other hand, is quite small, as the tidal range is of the order of $30 \mathrm{~cm}$ and the residual tidal currents are very small. The wind generated circulation is dominated by the prevailing $\mathrm{N}$, NE winds during the winter and the $\mathrm{W}, \mathrm{SW}$ winds during the summer. The shallow waters result to a very small response time of the basin (steady flow is reached after some hours of wind blow) and to strong wind generated currents.

The basin discretization using spatial steps $D x=3600 m$ and $D y=5800 m$ and the given bathymetry is depicted in Figures 1 and 2 respectively.

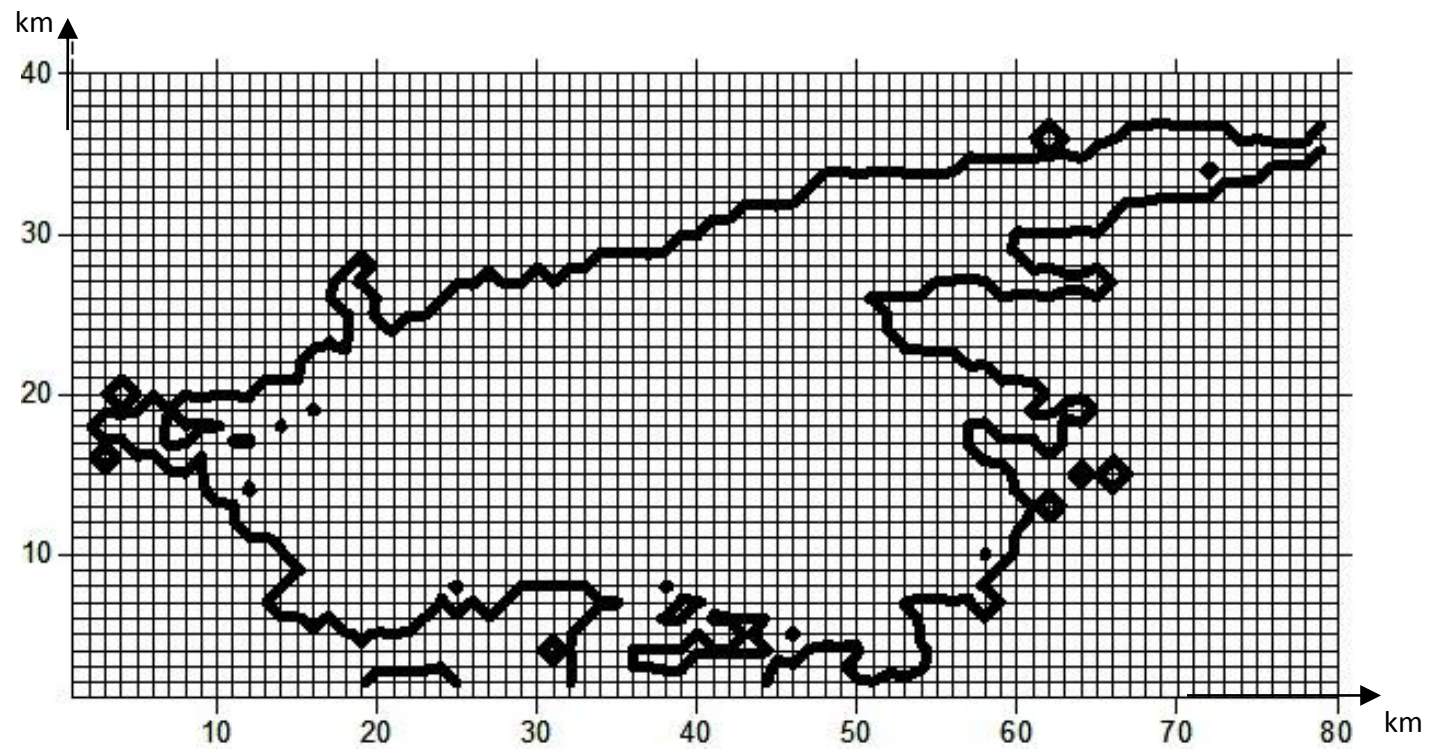

Figure 1. The sea of Azov's basin discretization using orthogonal grid ( $D x=3600 \mathrm{~m}, \mathrm{Dy}=5800 \mathrm{~m})$

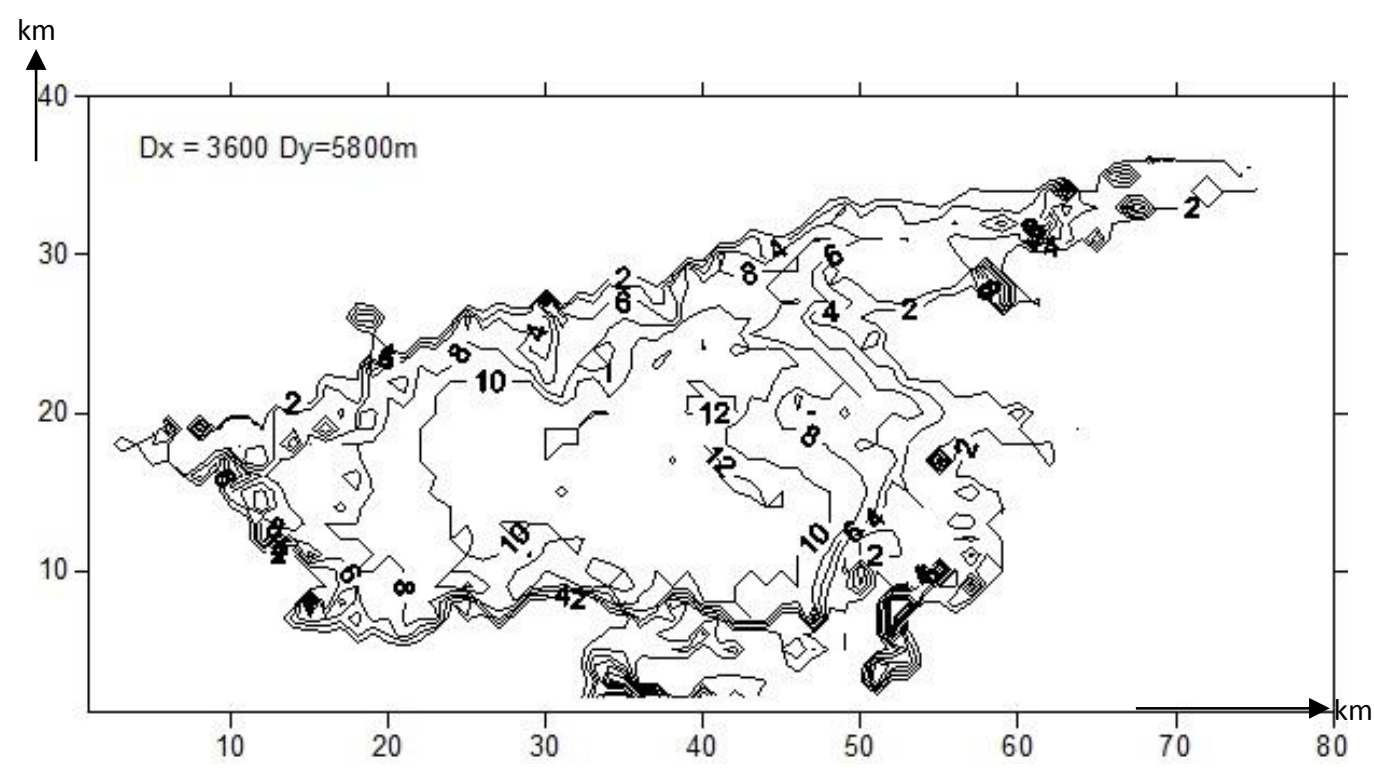

Figure 2. The sea of Azov's basin bathymetry 
The depth averaged and surface currents generated by $\mathrm{N}$ wind of $10 \mathrm{~m} \mathrm{sec}^{-1}$ are depicted in Figures 3 and 4 respectively. Reference vectors correspond to $\mathrm{m} \mathrm{sec}^{-1}$.

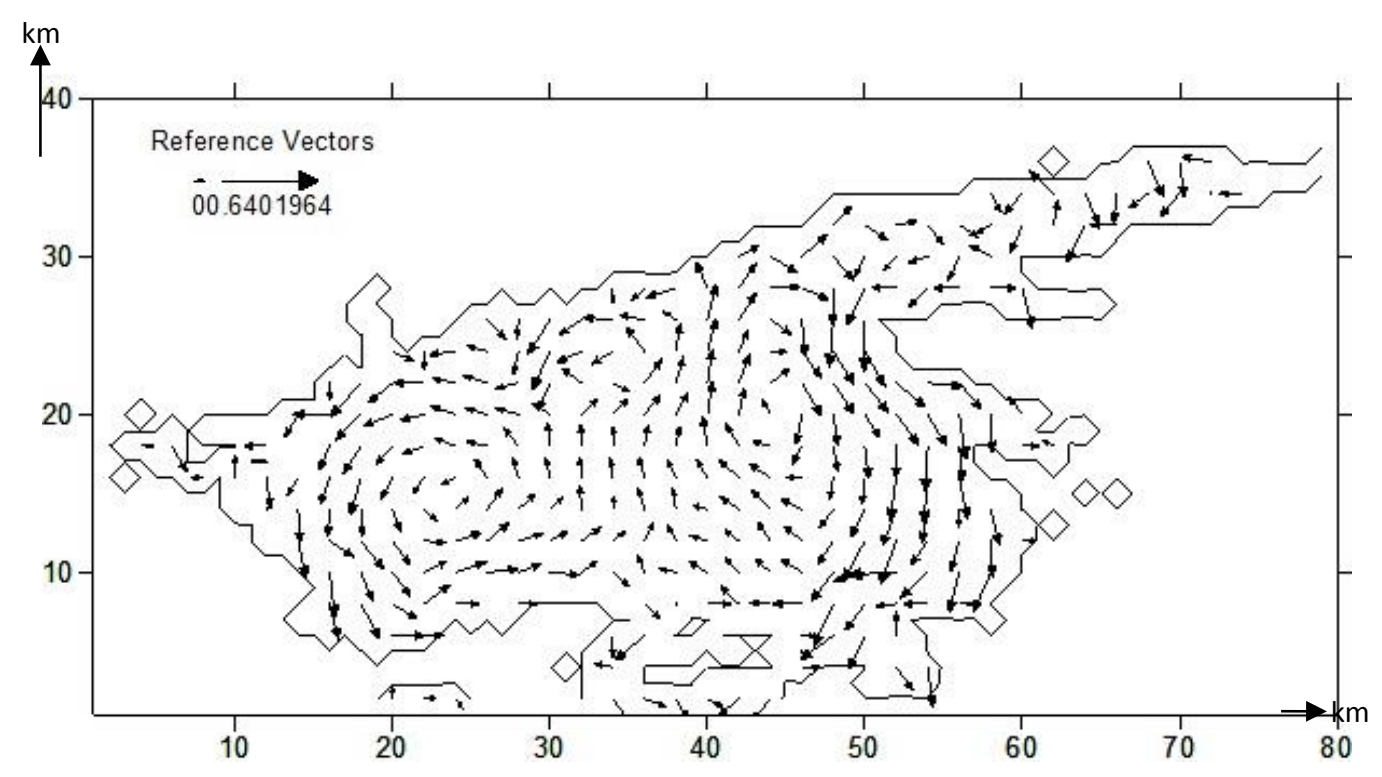

Figure 3. The depth averaged currents generated by $\mathrm{N}$ wind of $10 \mathrm{~m} \mathrm{sec}$



Figure 4. The surface currents generated by $\mathrm{N}$ wind of $10 \mathrm{~m} \mathrm{sec}^{-1}$

The currents due to Don annual mean discharge of $1000 \mathrm{~m}^{3} \mathrm{sec}^{-1}$ are depicted in the following Figure 5. 


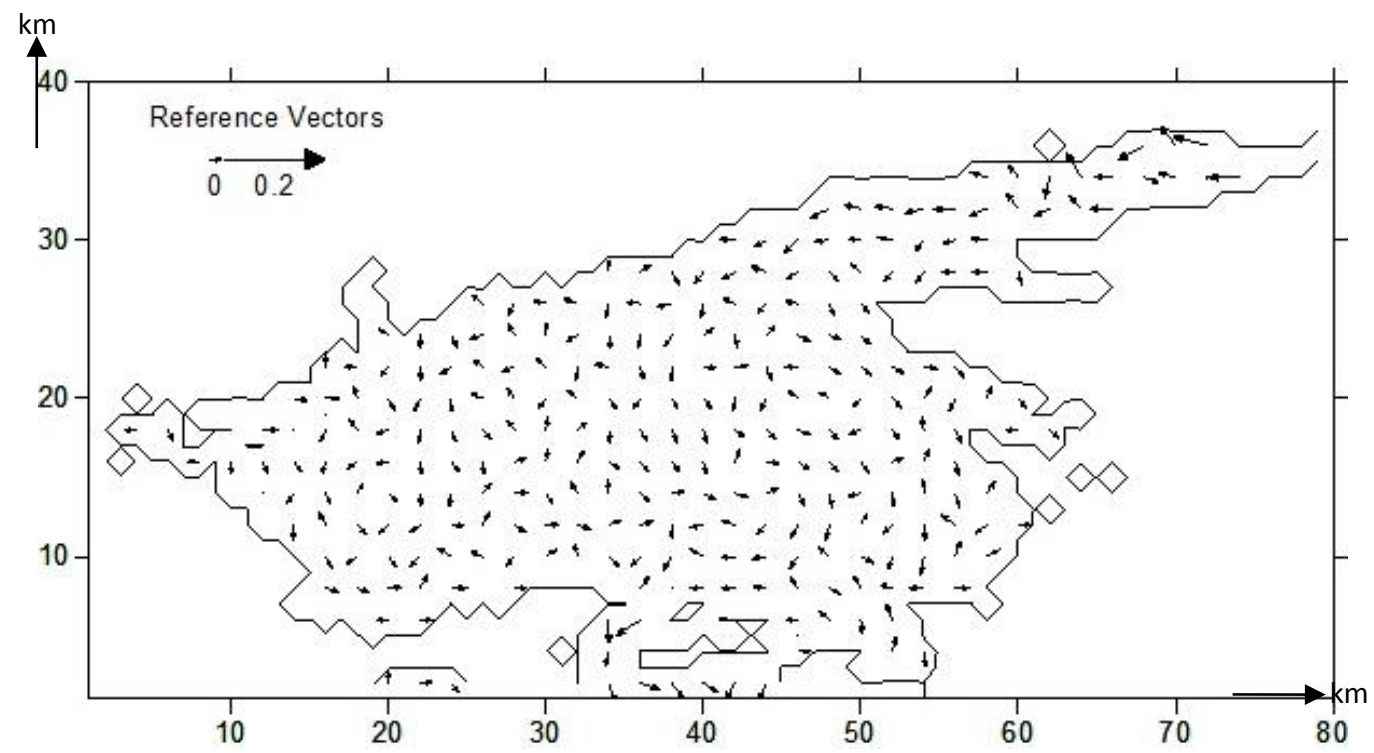

Figure 5. Currents generated by Don River (annual mean discharge $1000 \mathrm{~m}^{3} \mathrm{~s}^{-1}$ )

The waves developed during the windy periods are of medium size (wave heights of 2-3 $m$ at maximum). The coasts around the Azov Sea are low, prone to considerable trapping of oil masses reaching them.

According to the forecasted transportation development of the Eurasian Union (Kozlov and Zbaraschenko, 2009), the Azov sea is a main maritime transport route for ships moving from the Danube to the Caspian Sea. A main route from the Kerch straits to the port of Rostov-on-Don will be frequented by all kinds of vessels. This route, shown in Figure 6 , is considered as the main line for oil slicks accidental generation.

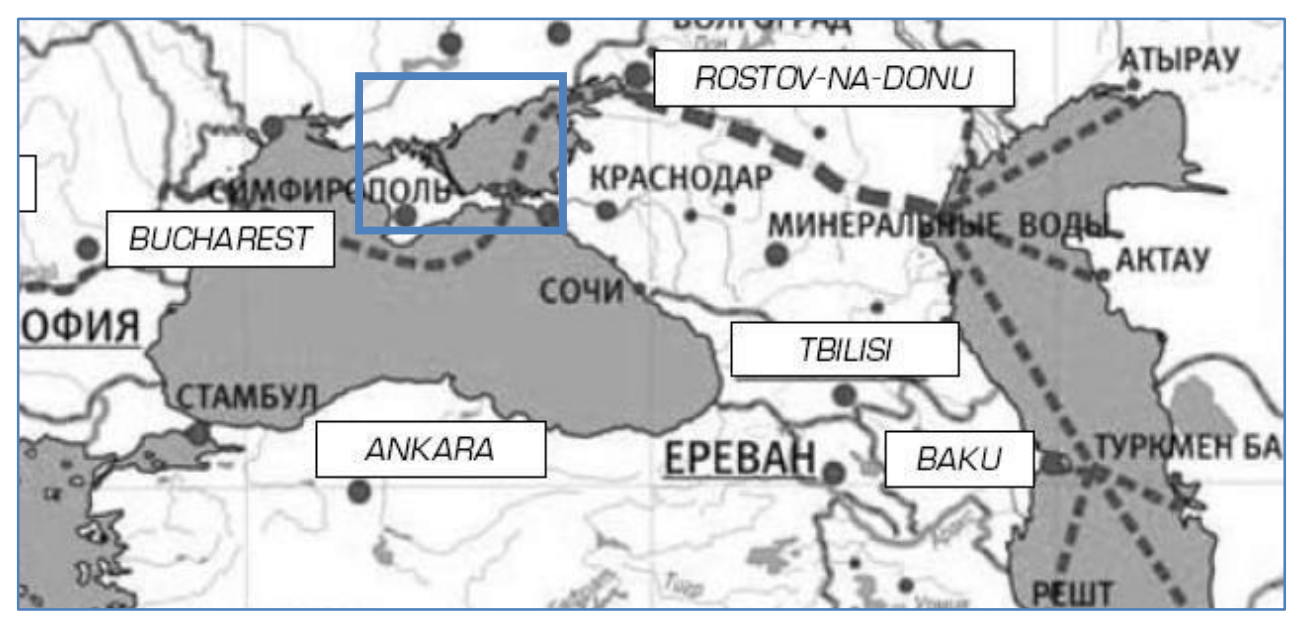

Figure 6. Main maritime transport route in Azov sea [Source: Kozlov and Zbaraschenko, 2009].

In agreement with the Ukrainian and Russian administrations, a number of coastal sites on the east and the west sides of the Azov Sea are included in the list of the Ramsar protected zones, depicted in Figure 7 (Lagutov, 2010). These areas are characterized by high ecological weights.

According to the presented physical conditions, the mean annual circulation in the Azov Sea is controlled by the wind climate and the Don River discharge. From available information (Peneva and Stips, 2004) on the monthly wind direction-intensity magnitudes, a time series of wind forcings is synthesized and the wind generated currents model is applied on annual basis. The wind generated currents components were superimposed to the corresponding wave drift components, calculated by a $1^{\text {st }}$ generation parametric model and to the river flow induced currents. 


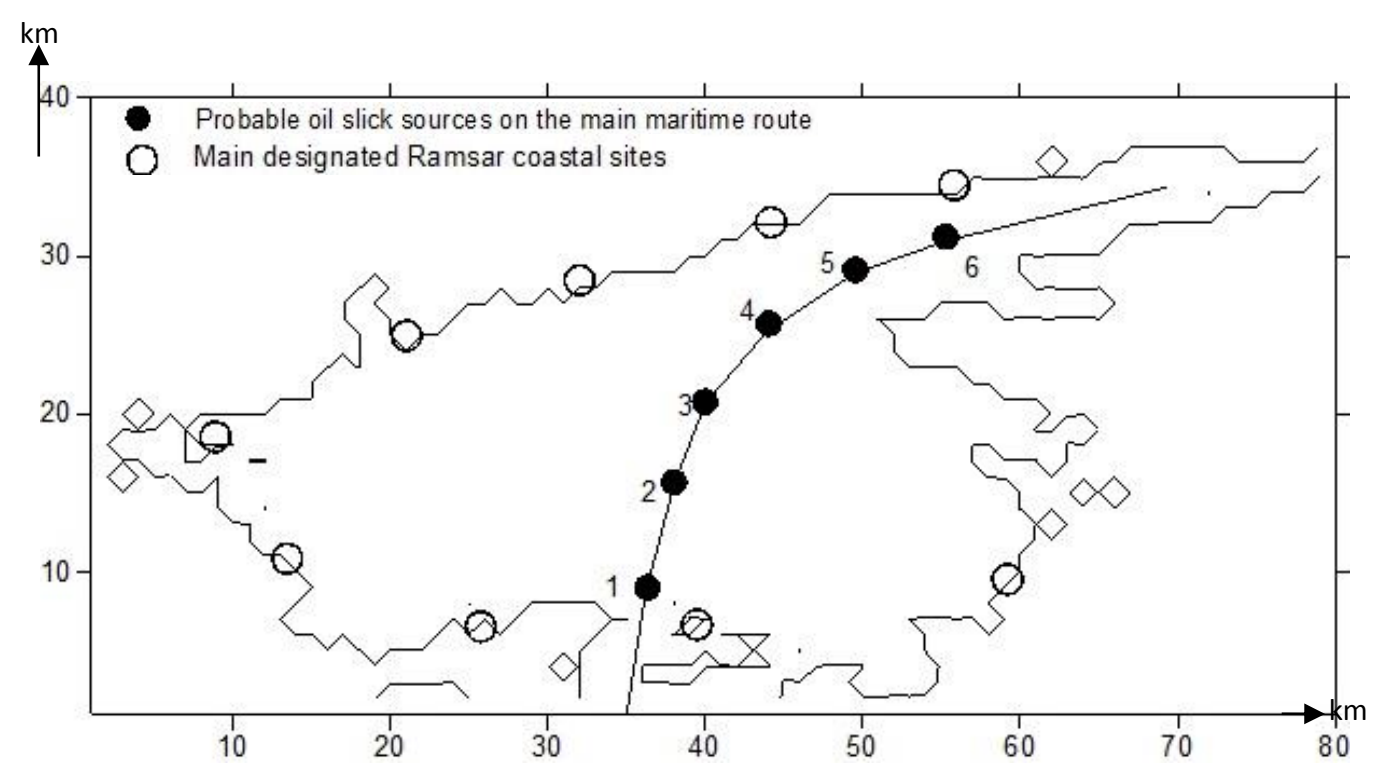

Figure 7. Probable oil slick sources and Ramsar protected coastal sites.

The candidate oil spill combating stations around the coast of Azov sea comprise the $M=6$ main port and coastal settlements, shown on the map of Figure 8.

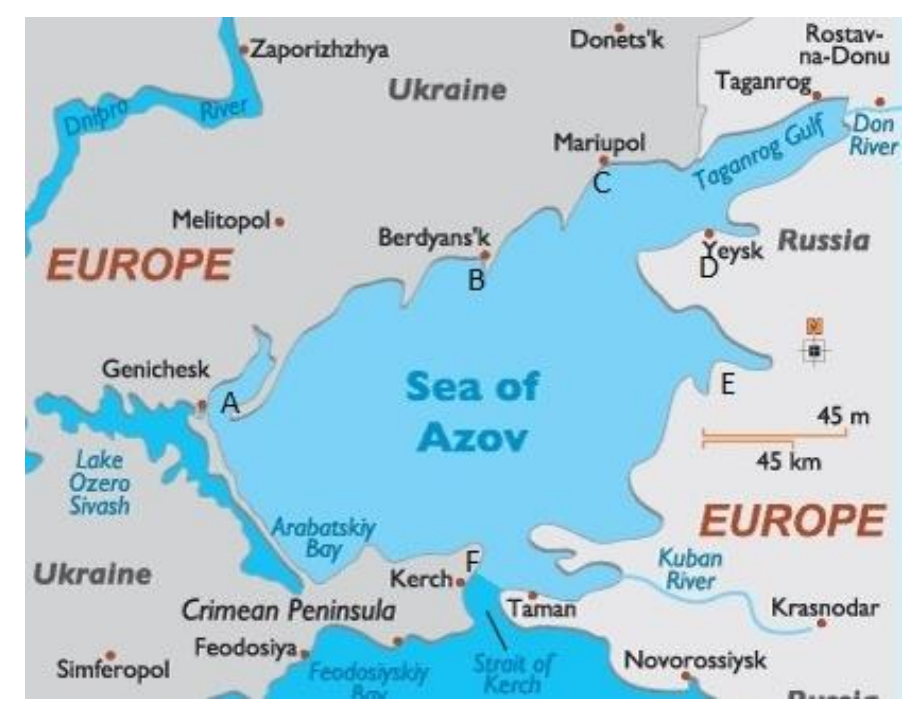

Figure 8. Candidate oil spill combating stations (namely A, B, C, D, E, F) on coastline.

A number of oil slick sources $(N=6)$, as shown in Figure 8 , was depicted and the annual impact on the coast was calculated via the oil slick model. The matrices of the coastal meshes pollution $P_{j k}^{i}$ (number of particles trapped on each coastal mesh), synthesized by the distributions illustrated in Figure 9, were stored for the total of the oil slick sources and weighted according to the ecological weight of each mesh (values of $W=1$ and 10 were used for plain coasts and coasts protected by Ramsar convention, respectively). 

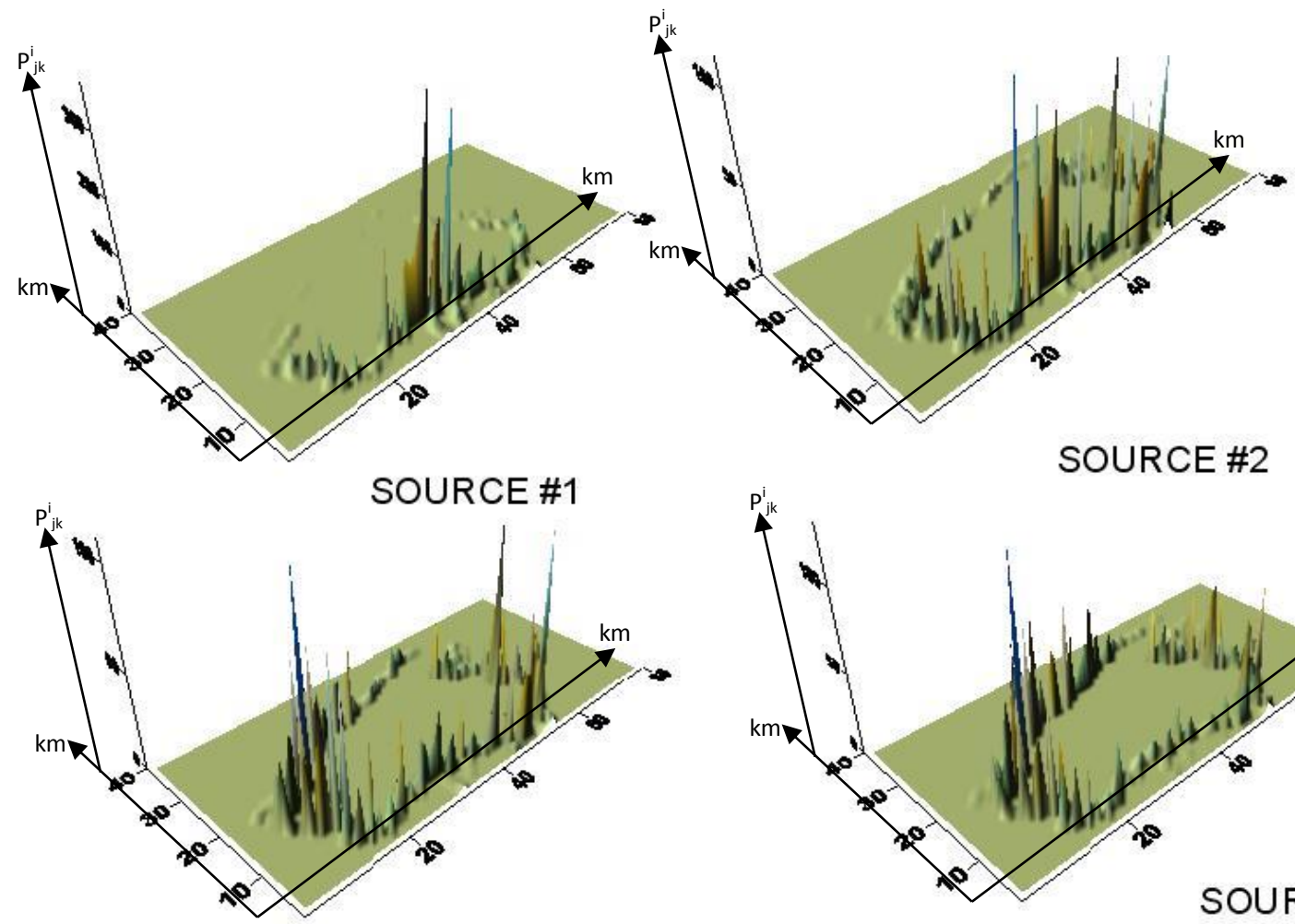

\section{SOURCE \#2}

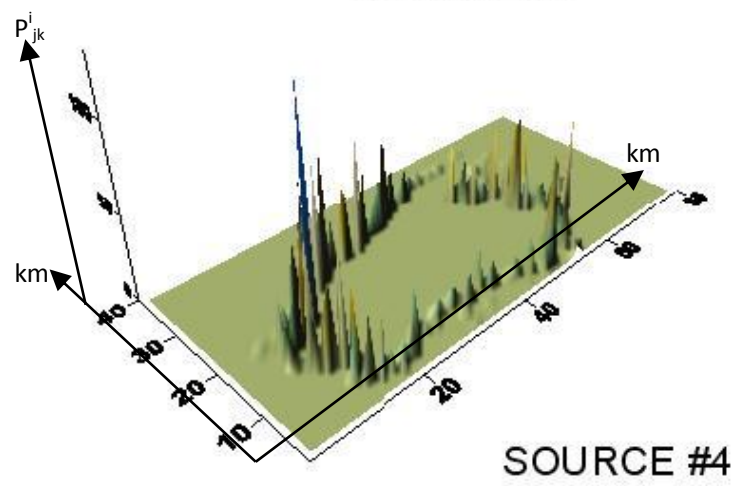

\section{SOURCE \#3}
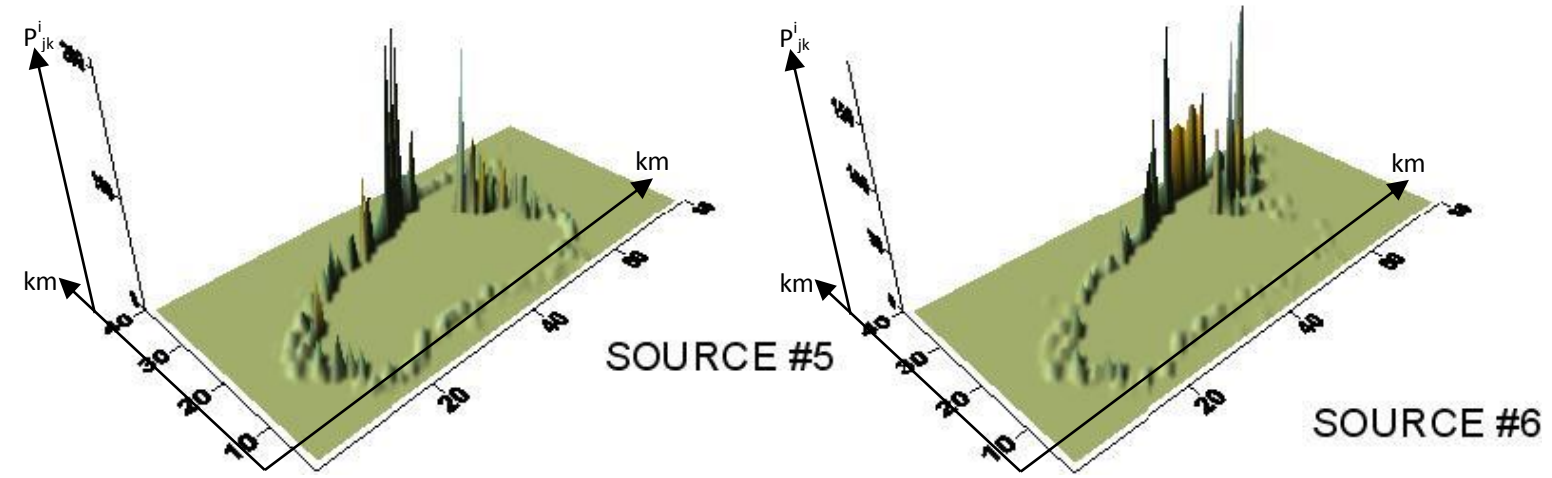

Figure 9. Mean annual impact on the coast from the six oil slick sources.

It must be noted that the order of magnitude in the vertical axis, i.e. the probability of oil pollution occurrence on the coastal meshes (number of beached particles), differs from source to source. In accordance with that, Table 1 indicates that the maximum environmental impact is caused by oil source 1 (see Fig. 7) at the entrance of Azov Sea, followed by oil source 6 near the exit of Don River, taking into account the ecological weighting factor of each mesh.

Table 1. Estimated environmental impact $E^{i}$ of the six oil sources and distances from the candidate combating stations (in km)

\begin{tabular}{ccccccc}
\hline Oil source & 1 & 2 & 3 & 4 & 5 & 6 \\
\hline$E^{i}$ & $\mathbf{8 2 2 8}$ & 5063 & 4803 & 5349 & 5303 & $\mathbf{6 3 4 0}$ \\
\hline Station A & 154 & 144 & 166 & 190 & 220 & 260 \\
\hline Station B & 130 & 93 & 48 & 40 & 54 & 95 \\
\hline Station C & 185 & 147 & 108 & 70 & 31 & 35 \\
\hline Station D & 190 & 160 & 130 & 90 & 60 & 30 \\
\hline Station E & 132 & 116 & 97 & 88 & 91 & 93 \\
\hline Station F & 25 & 55 & 90 & 140 & 180 & 220
\end{tabular}


The application of the aforementioned metric for their operational effectiveness gave the following results, shown in Table 2, leading to the final sorting of the candidate stations.

Table 2. The operational effectiveness values $O_{m}$ for each of the six candidate oil pollution combating stations.

\begin{tabular}{lcccccc}
\hline Combating station & A & B & C & D & E & F \\
\hline Value of operation effectiveness $O_{m}$ & 6.1 & 16.3 & $\mathbf{1 7 . 4}$ & 14.8 & 10.8 & $\mathbf{1 8 . 1}$ \\
\hline
\end{tabular}

As it was expected from the information provided in Table 1 in combination with the definition of the operational effectiveness, since the candidate combating station $\mathrm{F}$ is closest to the first oil source which demonstrates the highest environmental impact, the town of Kerch (combating station F) is considered more significant in terms of prioritization in selecting the combating stations, followed by the town of Mariupol (combating station C). It is to be noted that Kerch, being on the interface between the Azov sea and the Black sea is of most general importance, as a station there could mitigate the environmental damage due to a possible oil slick on the north boundary of the Black sea, such as the event of 2007 (Korotenko et al., 2010), with a tendency, due to weather conditions, to enter the Azov sea through the Kerch straits.

\section{Conclusions}

A decision support tool is presented and applied for the environmentally optimal allocation of oil spill combating stations along the coast of coastal basins like regional and marginal seas. The application of current models based on climatologic data, the concurrent application of oil spill models based on passive Lagrangian particles, lead to the statistically adequate quantification of the environmental impact on the coasts of the basin. A metric for the rational estimation of the operational effectiveness of coastal oil combating stations is proposed, facilitating the decision on the prioritizations for a number of such candidate stations. The application to the Azov Sea illustrated and clarified the proposed procedure, to a preliminary stage.

\section{ACKNOWLEDGMENTS}

This study has been produced with the assistance of the European Union, through the BSB JOP 2013-2017 (under the project with the acronym "BSB Net-Eco").

\section{REFERENCES}

Korotenko K.A., Bowman M.J. and Dietrich D.E. (2010), High resolution numerical model for predicting the transport and dispersal of oil spilled in the Black Sea, Terr. Atmos. Ocean. Sci., 21(1), 123-136.

Koutitas C. (1998), Mathematical Models in Coastal Engineering, Pentech Press, London.

Kozlov L. and Zbaraschenko V. (2009), Transcontinental shipping route Europe Central Asia, In: EDB Eurasian Integration Yearbook 2009, Vinokurov E. (Ed.), European Development Bank, Almaty.

Lagutov V. (2010), Environmental security in watersheds. The Sea of Azov, Springer.

Peneva E. and Stips A.K. (2004), Numerical simulations of Black sea and adjoined Azov sea, forced with climatological and meteorological reanalysis data, European Commission, Joint Research Centre.

Samuels W., Amstutz D., Bahadur R. and Ziemniak C. (2013), Development of a global oil spill modeling system, Earth Science Resource, 2, 1-10.

Sofianos S., Zafirakou-Koulouris A., Koutitas C., Mantziafou A., Tzali M. and Dermisi S. (2012), Oil spill dispersion forecasting with the aid of a 3D simulation model, Journal of Physical Science and Application, 10, 448-453.

The WAMDIG group (1988), The WAM model - A third generation ocean waves prediction model, American Meteorological Society, 18, 1775-1810. 